\title{
A fall in the previous 12 months predicts fracture in the subsequent 5 years in postmenopausal women
}

\author{
N. Afrin ${ }^{1}(D) \cdot$ R. Sund ${ }^{1} \cdot$ R. Honkanen ${ }^{1,2} \cdot H$. Koivumaa-Honkanen $^{1,2,3,4,5,6,7} \cdot$ T. Rikkonen ${ }^{1} \cdot$ L. Williams $^{8} \cdot$ H. Kröger $^{1,9}$
}

Received: 24 June 2019 / Accepted: 2 December 2019/Published online: 19 December 2019

(C) The Author(s) 2019

\begin{abstract}
Purpose The purpose of this study was to evaluate if a history of falls predicts future postmenopausal fractures and if this prediction variesaccording to frequency, mechanism, and severity of falls and site of fractures.

Methods This study used data from OSTPRE prospective cohort. Total study population consisted of 8744 postmenopausal women (mean age 62.2 years) who responded to postal enquiry in 1999 (baseline) and in 2004 (follow-up).

Results Women were classified by frequency (non/occasional/frequent fallers), mechanism (slip/nonslip), and severity (injurious/ non-injurious) of falls and fractures by site (major osteoporotic/other). A total of 1693 (19.4\%) women reported a fall during the preceding 12 months in 1999; 812 a slip fall, 654 a nonslip, 379 an injurious fall, and 1308 a non-injurious fall. A total of 811 women (9.3\%) sustained a fracture during the 5-year follow-up period (1999-2004); 431 major osteoporotic fractures and 380 other fractures. Compared with non-fallers, earlier falls predicted subsequent fractures with an OR of 1.41 (95\% CI 1.19-1.67, $p \leq 0.001$ ), 1.43 (95\% CI 1.14-1.80, $p=0.002$ ) for earlier slip falls, and 1.35 (95\% CI 1.04-1.74, $p=0.02$ ) for earlier nonslip falls. Earlier injurious falls predicted future fractures $(\mathrm{OR}=1.64,95 \% \mathrm{CI} 1.21-2.23, p \leq 0.01)$, especially other fractures $(\mathrm{OR}=$ $1.86,95 \%$ CI 1.24-2.80, $p \leq 0.01)$, but not major osteoporotic fractures $(\mathrm{OR}=1.37,95 \%$ CI $0.89-2.10, p=0.151)$. Fracture risk predictions for earlier non-injurious falls was $\mathrm{OR}=1.36,95 \% \mathrm{CI} 1.12-1.64, p=0.002$. These risk patterns remain same after adjustments.

Conclusion History of falls (especially injurious falls) predicts subsequent fractures (mainly other fractures compared with major osteoporotic fractures) inpostmenopausal women.
\end{abstract}

Electronic supplementary material The online version of this article (https://doi.org/10.1007/s00198-019-05255-5) contains supplementary material, which is available to authorized users.

N. Afrin
nadia.afrin@uef.fi
R. Sund
sund@uef.fi
R. Honkanen
honkanen@ fimnet.fi
H. Koivumaa-Honkanen
heli.koivumaa@kuh.fi
T. Rikkonen
toni.rikkonen@uef.fi
L. Williams
LANAW@ barwonhealth.org.au
H. Kröger
Heikki.kroger@kuh.fi

1 Kuopio Musculoskeletal Research Unit (KMRU), Surgery, Institute of Clinical Medicine, University of Eastern Finland (UEF), P.O. Box 1627, 70211 Kuopio, Finland

2 Department of Psychiatry, University Hospital of Oulu, Oulu, Finland

3 Institute of Clinical Medicine (Psychiatry), University of Eastern Finland, Kuopio, Finland

4 Department of Psychiatry, South-Savonia Hospital District, Mikkeli, Finland

5 Department of Psychiatry, North Karelia Central Hospital, Joensuu, Finland

6 Department of Psychiatry, SOTE, Iisalmi, Finland

7 Department of Psychiatry, Oulu University Hospital, Oulu, Finland

8 IMPACT Strategic Research Centre, School of Medicine, Deakin University, Geelong, Australia

9 Department of Orthopedics, Traumatology and Hand Surgery, Kuopio University Hospital, Kuopio, Finland 
Summary We aimed to investigate if history of falls (frequency, mechanism, and severity) is a predictor of future fractures in postmenopausal women. Our results indicate that history of falls (especially injurious falls) appeared to be an indicator for subsequent fracture overall. Earlier injurious falls were stronger predictors for future other fractures than for typical major osteoporotic fractures.

Keywords Fall $\cdot$ Fracture $\cdot$ Injurious fall

\section{Introduction}

Falls in the elderly are common [1] and result in fractures and other serious health consequences [2]. Among subjects aged 65 years or over, falls are the leading cause of injury-related death and hospitalization [3]. Thus, fall-induced injuries result in a substantial economic burden worldwide [4]. Research has shown a history of falls to be associated with a higher probability for future falls and risk of subsequent fractures [5-9]. In cold climate countries, slipping is a common fall mechanism and results often in injuries (injurious falls) [10]. Thus far, longitudinal studies on how history of falls predicts future fractures have not been determined according to frequency, mechanism (slip/nonslip), or severity (injurious/non-injurious) of the fall [11-13].

Previously, we have found that falling risks (especially nonslip falls) increased in women with multimorbidity (multiple chronic conditions) [14]. It is probable that due to effects of health disorders, women who have multiple nonslip falls are more unwell and less physically active compared with women with slip falls [15]. Falling events resulting in injury also reflect the overall health condition of the individuals [16]. The aim of the present study was to determine if an overall history of falls (frequency, mechanism, and severity) or its parts are useful predictors of future fracture in postmenopausal women.

\section{Materials and methods}

\section{Study design and subjects}

This is a prospective cohort study. The study population originated from the Kuopio Osteoporosis Risk Factor and Prevention Study (OSTPRE) initiated in 1989. The baseline selfadministered postal enquiry of OSTPRE was sent to all women born in 1932-1941 $(N=14,220)$ aged $47-56$ years and living in Kuopio Province, Eastern Finland. Follow-up data has been collected by subsequent postal enquiries at 5 -year intervals.

The present study included a total of 8744 women who responded to the fall questions in 1999 (baseline of the present study) and fracture questions in 2004 with no other inclusion criteria. At baseline, the mean age of the participants was 62.2 (range 57-66) years (SD 2.9) and all women were postmenopausal. The ethics committee of Kuopio University Hospital approved the OSTPRE study and participants provided a written informed consent.

\section{Measurement of variables}

\section{Falls (exposure)}

For the present study, we used self-reported falls. A definition of a fall was not mentioned in the questionnaire, due to the Finnish language having different words for falls on the same level versus falls from height. At baseline (May 1999), the participants were asked about history of falls, via the question "How many times have you fallen during the last 12 months?" If a fall was reported, they were further asked "How did you fall last time" with the following alternatives: (1) fall on stairs, (2) fall from level, (3) slipping on level, (4) stumbling or tripping on level, and (5) otherwise on level, specify. The severity of the falling event was determined via the question "Did the last fall result in medical attention?"

The women were classified according to frequency of falls, i.e., (1) non-faller, (2) occasional faller, (one fall), and (3) frequent faller (more than one fall). The falling mechanism was categorized as (1) slip on the same level and (2) nonslip (i.e., any other than slip) on the same level according to their last falling event. Falls were also categorized by severity: (1) injurious (self-reported medically attended falls) and (2) noninjurious. Falls from a bicycle or while skiing were not counted as falls. Women who reported no falls (non-fallers) were considered as the reference group for all analyses (occasional, frequent, slip, nonslip, injurious, or non-injurious).

\section{Fractures (outcome)}

At follow-up (in 2004), the participants were asked about the occurrence of fracture: "Have you had fractures diagnosed by physician after May 1999?" Those who reported a fracture were then asked, "which bone was fractured, how it was diagnosed and where it was treated?" The follow-up time for incident fractures was 5 years between the 1999 and 2004 questionnaire. All self-reported fractures were confirmed by patient records. In this analysis, 
the first fracture in each fracture site per person occurring during this follow-up time was included.

According to the FRAX (fracture risk prediction model) tool, fractures occurring at the spine, hip, distal forearm, and proximal humerus are considered major osteoporotic fractures [17], which by definition include low trauma (i.e., fall from a standing height or less) [18]. Thus, we classified the fractures into (1) major osteoporotic fracture (spine, hip, distal forearm, and proximal humerus) and (2) other fractures (other than major osteoporotic fractures, including, e.g., chest region, hand, forearm, and elbow; femur, knee and leg; ankle and foot; skull, pelvis) fractures. We investigated future fracture risk in these categories according to frequency (no/occasional /frequent), mechanism (slip/nonslip), and severity (injurious/non-injurious) of earlier falls.

\section{Covariates}

From the baseline enquiry, covariates and potential confounders were chosen based on literature and according to their potential association with fractures and falls. They included baseline age (years), body mass index (BMI; kg/ $\mathrm{m}^{2}$ ), dairy calcium intake ( $\mathrm{mg} /$ day), number of prescribed medications, number of chronic health disorders, current smoking (no/yes), alcohol use (no/yes), leisure physical activity (no/yes), restricted mobility (no/yes), falls during the last 12 months, and use of estrogen hormone therapy (no use/irregular use/continuous use) during 1999-2004. Previously, we have found that the effect of hormone therapy is transient so that only current but not past use prevents fractures [19]. Therefore, we used follow-up hormone therapy variable during 1999-2004 (instead of baseline measurement). Dairy calcium intake was measured via the questions (1) How many deciliters (1glass $=$ $2 \mathrm{dl} ; 1 \mathrm{dl}=120 \mathrm{mg}$ of calcium) dairy products (milk, sour milk, yogurt, sour whole milk) do you use daily? (2) How many cheese slices (1 slice $=87 \mathrm{mg}$ of calcium) do you eat daily?

\section{Statistical analyses}

Statistical analysis was conducted using SPSS, version 25.0. A $t$ test (Student's $t$ test) for continuous variables and chisquare tests for categorical variables were used to identify the association between each study variable and fractures. Logistic regression models were used to analyze the crude and adjusted risk of future fractures according to frequency, mechanism, and severity of earlier falls. The results were reported as odds ratios (OR) with $95 \%$ confidence intervals ( $95 \% \mathrm{CI})$ and $p$ values.

\section{Results}

\section{Baseline characteristics and incidences of falls and fractures}

At the time of fall enquiry in 1999 , the mean age of the participants was 62.2 (range 57-66) years (SD 2.9) and all women were postmenopausal. The women were on average 13 years since menopause as the mean age of menopause was 49.2 years (SD 4.7).

As presented in Fig. 1, 7051 of 8744 women (80.6\%) reported no falls (non-fallers), 941 (10.8\%) women at least one fall (occasional fallers), and 752 (8.6\%) women more than one fall (frequent fallers) in the preceding 12 months. From the total study population ( $n=8744)$, a total of 227 women did not answer the questions regarding mechanism of fall (slip/ nonslip) and a total of 6 women did not answer the question regarding severity of fall (injurious/non-injurious). The number of women who reported slip or nonslip falls as the mechanism of their last fall were $812 / 8517(9.5 \%)$ and $654 / 8517$ $(7.7 \%)$, respectively. A total of 379/8738 (4.4\%) women reported falls requiring medical attention (injurious falls), and out of these 379 women, 131 (34.6\%) women reported a fracture as the outcome of the event.

In the 5-year follow-up (1999-2004), 811/8744 (9.3\%) women reported fractures which were confirmed via medical records (Fig. 1). Of these 811 women, $431 / 811$ (53.1\%) reported major osteoporotic fractures, 380/811 (46.9\%) solely other fractures, and 38/811 (4.7\%) women had both types of fractures. In general, the mean number of prescribed medications and number of chronic health disorders were higher among women with at least one fracture than among women with no fracture. History of previous falls was significantly higher among women with fracture compared to women with no fracture (Table 1). In addition, use of hormone therapy was significantly lower among women with fracture (Table 1) and continuous use of hormone therapy showed a preventive effect on future fracture risks $(\mathrm{OR}=0.45,95 \% \mathrm{CI}=0.41-0.72$, $p$ values $<0.001$ ) compared with irregular use or no use.

\section{Future fracture risks by frequency, mechanism, and severity of earlier falls}

Compared with the 7051 women who reported no fall (reference group) at the baseline enquiry in 1999, the OR for fracture among women who reported a previous fall was 1.41 (95\% CI 1.19-1.67, $p \leq 0.001)$, women who reported one fall (occasional fallers) was 1.38 (95\% CI $1.11-1.71, p=0.003)$, and women who reported more than one fall (frequent fallers) was 1.45 (95\% CI 1.15 $1.83, p=0.002$ ) (Table 2) in unadjusted analyses.

In fracture categories, the risk for other fractures related to fall history was higher than the corresponding risk for major 
Fig. 1 Distribution of the study population according to the different type of falls and fractures

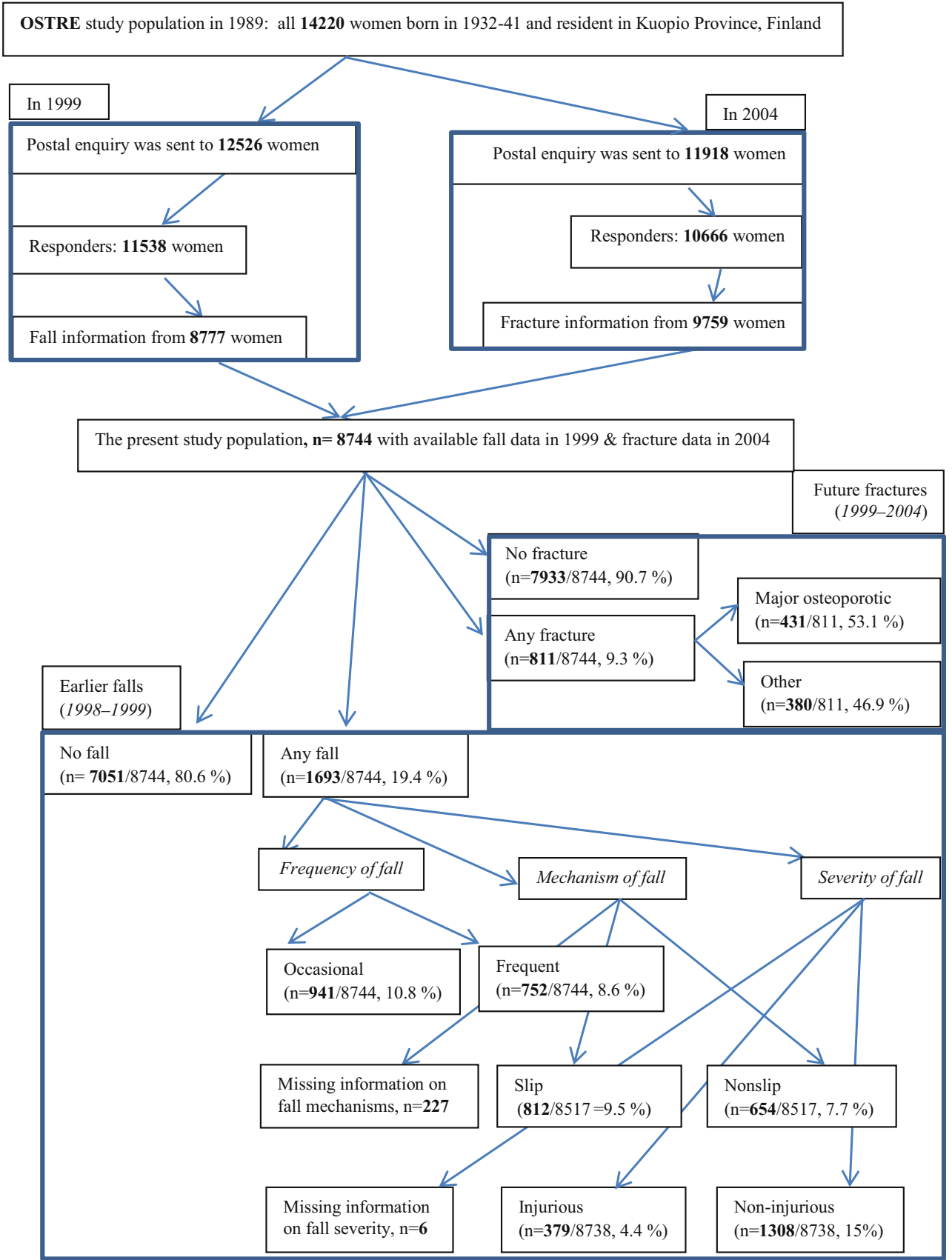

osteoporotic fractures. Women who reported a previous fall were at higher risk of future other fractures $(\mathrm{OR}=1.54,95 \%$ CI $1.22-1.95, p \leq 0.001)$ than major osteoporotic fractures $(\mathrm{OR}=1.26,95 \%$ CI $0.99-1.58, p=0.052)$ compared with non-fallers (reference group) (Table 2). With the same reference group, the corresponding ORs for future other fractures in women with previous slip falls was 1.59 (95\% CI 1.17$2.17, p=0.003$ ) and in women with previous nonslip falls was 1.50 (95\% CI 1.06-2.12, $p=0.02)$. Earlier injurious falls strongly predicted the risk of future other fracture $(\mathrm{OR}=$ $1.86,95 \%$ CI $1.24-2.80, p \leq 0.01)$, but not the risk of major osteoporotic fractures $(\mathrm{OR}=1.37,95 \%$ CI $0.89-2.10, p=$
0.151). In addition, women who fell frequently (more than one fall) were at greater risk of future fracture (major osteoporotic/other) than those who fell occasionally (one fall) (Table 2). The future fracture risk estimation remained almost same following adjustment for clinically relevant predictors (age, BMI, dairy calcium intake, number of prescribed medications, number of chronic health disorders, use of estrogen hormone therapy (1999-2004), current smoking, alcohol use, leisure physical activity, and restricted mobility) (Table 2).

In regard to site-specific fractures, the risk for subsequent fracture was also increased for most sites (mainly other fractures) due to earlier falls; however, most failed to reach 
Table 1 Baseline characteristics of the study population according to fracture

\begin{tabular}{|c|c|c|c|}
\hline Baseline characteristics & $\begin{array}{l}\text { No fracture } \\
\quad(n=7933) \\
\text { Mean (SD) }\end{array}$ & $\begin{array}{l}\text { Any fracture } \\
\quad(n=811) \\
\text { Mean (SD) }\end{array}$ & $p$ value* \\
\hline Age, years & $62.2(2.9)$ & $62.3(3.0)$ & 0.29 \\
\hline Body mass index, $\mathrm{kg} / \mathrm{m}^{2}$ & $27.49(4.51)$ & $27.52(4.41)$ & 0.83 \\
\hline Dairy calcium intake, $\mathrm{mg} /$ day & $850(370)$ & $828(361)$ & 0.11 \\
\hline Number of chronic health disorders & $2.32(1.78)$ & $2.45(1.87)$ & 0.05 \\
\hline Number of prescribed medications & $\begin{array}{l}1.97(1.95) \\
\text { Proportion as \% }\end{array}$ & $\begin{array}{l}2.16(2.11) \\
\text { Proportion as \% }\end{array}$ & 0.01 \\
\hline \multicolumn{4}{|c|}{${ }^{\mathrm{a}}$ Use of estrogen hormone therapy in 1999-2004 } \\
\hline No use $(n=6845)$ & $77.70(n=6167)$ & $83.60(n=678)$ & \\
\hline Irregular use $(n=786)$ & $9.10(n=721)$ & $8.00(n=65)$ & $<0.001$ \\
\hline Continuous use $(n=1113)$ & $13.20(n=1045)$ & $8.40(n=68)$ & $<0.001$ \\
\hline Current smoking (yes, $n=611$ ) & $6.90(n=548)$ & $7.80(n=63)$ & 0.36 \\
\hline Alcohol use (yes, $n=4578$ ) & $53.10(n=4126)$ & $56.90(n=452)$ & 0.05 \\
\hline Leisure physical activity (yes, $n=6079$ ) & $71.90(n=5513)$ & $72.60(n=566)$ & 0.70 \\
\hline Restricted mobility (yes, $n=352$ ) & $4.20(n=314)$ & $5.00(n=38)$ & 0.30 \\
\hline \multicolumn{4}{|l|}{ Falling history (in the past 12 months) } \\
\hline No fall $(n=7051)$ & $81.20(n=6440)$ & $75.30(n=611)$ & \\
\hline Occasional fall $(n=941)$ & $10.50(n=832)$ & $13.40(n=109)$ & $<0.001$ \\
\hline Frequent fall $(n=752)$ & $8.30(n=661)$ & $11.20(n=91)$ & $<0.001$ \\
\hline
\end{tabular}

$S D$ standard deviation

${ }^{a}$ Use of estrogen hormone therapy in 1999-2004 was obtained from the 2004 enquiry as continuous use of hormone therapy appeared to prevent falls in these women ${ }^{19}$

$* t$ test (Student's $t$ test) for continuous and chi-square tests for categorical variables are used to find the difference between no fractures and fracture groups statistical significance (Fig. 2). Of the fall's categories (frequency, mechanism, and severity), injurious falls tended to be associated with the highest risk of site-specific fractures compared with the other categories (Appendix Table 1).

\section{Loss analysis}

The cohort members responded better to fracture questions in $2004(n=9759)$ than to fall questions in $1999(n=8744)$ (Fig. 1). A total of 1015 women had fracture information but no fall information. The percentages of women with incident fractures during 1999-2004 were similar in women without and with information on falls $(94 / 1015)=9.26 \%$ vs. $(811 / 8744)=$ $9.27 \%$, respectively.

\section{Discussion}

The present study shows that a history of falls (especially injurious falls) is an important risk factor for future fracture, in particular for other fractures compared to major osteoporotic fractures among postmenopausal women. To our knowledge, fracture risk (major osteoporotic vs other) according to mechanism (slip/nonslip) and severity (injurious/non- injurious) of previous falls has not been previously examined in a prospective cohort study.

In the present study, the annual fall incidence rate (20\%) was less than previously reported (30\%) in studies including elderly women aged 65 years or over [1]. The mean age [62.2 years (range 57-66)] of the included study population likely explains the lower incidence rate, as rate of falls increases with increasing age $[5,20]$. Slipping was the most common falling mechanism and the proportion of slip falls was clearly higher than in most studies conducted in warmer climates [21]. The long and icy winter season in the cold climate countries leads to frequent outdoor slip falls, which explains their higher occurrence compared to nonslip falls in the present study population [22].The self-reported use of estrogen hormone therapy was higher among women with no fracture and has a significant preventive effect on future fractures. This observation is in alignment with our previous studies from the OSTPRE follow-up [19, 23]. Although, we previously found that the use of estrogen therapy appeared to have a preventive effect on falls in early but not in late menopausal women [24]. It is possible that the effects of hormone therapy on fall risk reduce with age.

By understanding how frequency, mechanism, and severity of previous falls modify the risk of future fractures (major osteoporotic vs other), specific measures for 
Table 2 Unadjusted and adjusted risks (ORs) of fractures related to history of falls in comparison to non-faller risk

\begin{tabular}{|c|c|c|c|c|}
\hline Type of fall & & $\begin{array}{l}\text { Any fracture } \\
\left({ }^{\mathrm{a}} n=811\right)\end{array}$ & $\begin{array}{l}\text { Major osteoporotic fracture } \\
(n=431)\end{array}$ & Other fracture $(n=380)$ \\
\hline & & \multicolumn{3}{|c|}{ OR, $95 \% \mathrm{CI}, p$ value } \\
\hline \multicolumn{5}{|l|}{ Any fall } \\
\hline \multirow[t]{2}{*}{ Total $(n=1693)$} & Unadjusted & $1.41(1.19-1.67) * * *$ & $1.26(0.99-1.58)$ & $1.54(1.22-1.95) * * *$ \\
\hline & Adjusted & $1.38(1.14-1.66) * * *$ & $1.15(0.88-1.49)$ & $1.61(1.25-2.09) * * *$ \\
\hline \multirow[t]{2}{*}{ Occasional $(n=941)$} & Unadjusted & $1.38(1.11-1.71) * *$ & $1.35(1.02-1.80) *$ & $1.36(1.00-1.86) *$ \\
\hline & Adjusted & $1.35(1.07-1.72) *$ & $1.28(0.93-1.75)$ & $1.40(1.00-1.96) *$ \\
\hline \multirow[t]{2}{*}{ Frequent $(n=752)$} & Unadjusted & $1.45(1.15-1.83) * *$ & $1.14(0.81-1.59)$ & $1.77(1.30-2.40) * * *$ \\
\hline & Adjusted & $1.42(1.09-1.85) * *$ & $0.98(0.66-1.47)$ & $1.89(1.35-2.65) * * *$ \\
\hline \multicolumn{5}{|l|}{ Slip fall } \\
\hline \multirow[t]{2}{*}{ Total $(n=812)$} & Unadjusted & $1.43(1.14-1.80) * *$ & $1.24(0.91-1.70)$ & $1.59(1.17-2.17) * *$ \\
\hline & Adjusted & $1.47(1.15-1.89) * *$ & $1.25(0.89-1.76)$ & $1.67(1.19-2.35) * *$ \\
\hline \multirow[t]{2}{*}{ Occasional $(n=476)$} & Unadjusted & $1.38(1.03-1.85) *$ & $1.41(0.96-2.06)$ & $1.29(0.84-1.98)$ \\
\hline & Adjusted & $1.33(0.96-1.85)$ & $1.36(0.90-2.06)$ & $1.26(0.78-2.03)$ \\
\hline \multirow[t]{2}{*}{ Frequent $(n=336)$} & Unadjusted & $1.51(1.08-2.10) *$ & $1.01(0.61-1.69)$ & $2.04(1.34-3.09) * * *$ \\
\hline & Adjusted & $1.67(1.17-2.39) * *$ & $1.09(0.63-1.90)$ & $2.26(1.45-3.53) * * *$ \\
\hline \multicolumn{5}{|l|}{ Nonslip fall } \\
\hline \multirow[t]{2}{*}{ Total $(n=654)$} & Unadjusted & $1.35(1.04-1.74) *$ & $1.18(0.83-1.68)$ & $1.50(1.06-2.12) *$ \\
\hline & Adjusted & $1.30(0.98-1.73)$ & $1.05(0.70-1.56)$ & $1.62(1.11-2.36) *$ \\
\hline \multirow[t]{2}{*}{ Occasional $(n=383)$} & Unadjusted & $1.30(0.93-1.81)$ & $1.17(0.75-1.85)$ & $1.41(0.89-2.22)$ \\
\hline & Adjusted & $1.30(0.91-1.85)$ & $1.10(0.67-1.80)$ & $1.51(0.93-2.45)$ \\
\hline \multirow[t]{2}{*}{ Frequent $(n=271)$} & Unadjusted & $1.41(0.97-2.06)$ & $1.19(0.70-2.02)$ & $1.63(0.98-2.69)$ \\
\hline & Adjusted & $1.31(0.84-2.02)$ & $0.88(0.45-1.75)$ & $1.77(1.02-3.06) *$ \\
\hline \multicolumn{5}{|l|}{ Injurious fall } \\
\hline \multirow[t]{2}{*}{ Total $(n=379)$} & Unadjusted & $1.64(1.21-2.23) * *$ & $1.37(0.89-2.10)$ & $1.86(1.24-2.80) * *$ \\
\hline & Adjusted & $1.64(1.18-2.29) * *$ & $1.38(0.87-2.20)$ & $1.85(1.18-2.90) * *$ \\
\hline \multirow[t]{2}{*}{ Occasional $(n=299)$} & Unadjusted & $1.58(1.12-2.24) * *$ & $1.45(0.91-2.31)$ & $1.65(1.02-2.66) *$ \\
\hline & Adjusted & $1.54(1.06-2.25) *$ & $1.41(0.85-2.35)$ & $1.61(0.95-2.73)$ \\
\hline \multirow[t]{2}{*}{ Frequent $(n=80)$} & Unadjusted & $1.86(1.00-3.46) *$ & $1.07(0.39-2.93)$ & $2.70(1.29-5.65) * *$ \\
\hline & Adjusted & $2.05(1.06-3.97) *$ & $1.29(0.46-3.60)$ & $2.78(1.24-6.23) * *$ \\
\hline \multicolumn{5}{|l|}{ Non-injurious fall } \\
\hline \multirow[t]{2}{*}{ Total $(n=1308)$} & Unadjusted & $1.36(1.12-1.64) * *$ & $1.23(0.95-1.59)$ & $1.46(1.12-1.89) * *$ \\
\hline & Adjusted & $1.31(1.06-1.62) * *$ & $1.08(0.81-1.46)$ & $1.55(1.16-2.07) * *$ \\
\hline \multirow[t]{2}{*}{ Occasional $(n=640)$} & Unadjusted & $1.29(1.00-1.68) *$ & $1.31(0.93-1.85)$ & $1,24(0.85-1.81)$ \\
\hline & Adjusted & $1.27(0.95-1.69)$ & $1.21(0.83-1.77)$ & $1.31(0.87-1.98)$ \\
\hline \multirow[t]{2}{*}{ Frequent $(n=668)$} & Unadjusted & $1.41(1.10-1.81) * *$ & $1.15(0.81-1.64)$ & $1.67(1.20-2.33) * *$ \\
\hline & Adjusted & $1.36(1.02-1.80) *$ & $0.95(0.62-1.46)$ & $1.79(1.25-2.57) * *$ \\
\hline
\end{tabular}

${ }^{\mathrm{a}} n$, number of women; any fall, slip/nonslip/unknown falls

OR odds ratio, $95 \%$ confidence interval

$* p \leq 0.05$

$* * p \leq 0.01$

$* * * p \leq 0.001$

Adjusted for age, BMI, dairy calcium intake, number of prescribed medications, number of chronic health disorders, use of estrogen hormone therapy (1999-2004), current smoking, alcohol use, leisure physical activity, and restricted mobility

fracture prevention can be developed accordingly [13, 25-27]. In the present study, we found higher future fracture risk due to previous slip falls $(\mathrm{OR}=1.43)$ compared with previous nonslip falls $(\mathrm{OR}=1.35)$. However, there was no statistically significant difference between the two (slip vs nonslip) risk predictions (Table 2). A plausible explanation for the observed increase in fracture risk prediction due to slip falls could be that women who have 
Fig. 2 Specific future fracture risks (odds ratios with $95 \% \mathrm{CIs}$ ) related to all and injurious earlier fall in comparison with women with no earlier falls. *No future skull fractures were observed for women with earlier injurious fall

\section{Major Osteoporotic}

Spine

Distal forearm

Proximal humerus

Hip

\section{Other}

Pelvis

Chest region

Femur, knee and leg

Hand, forearm and elbow

Ankle and foot

Skull

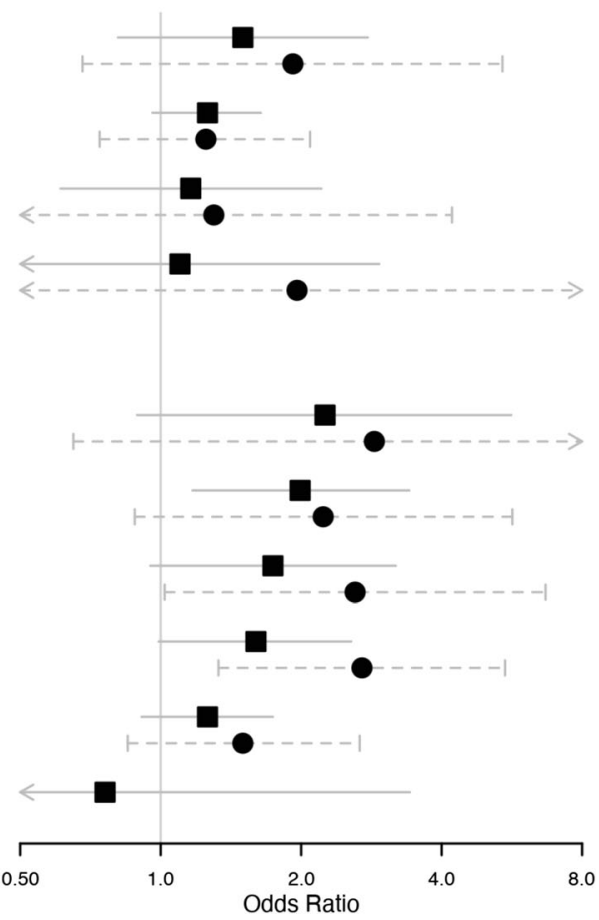

had previous slip falls are more physically active and capable of moving outdoors more often than women with a previous history of nonslip falls. These women would have greater exposure to slippery conditions which is a known risk factor for fracture [14, 15].

We observed that previous slip and nonslip falls were associated with other fractures but not major osteoporotic fractures. In addition, the risk of other fractures was considerably greater in relation to previous (injurious) falls. The greater other fractures risk related to previous history of falls (frequency, mechanism, and severity) could indicate that these women are healthier; they may have stronger bones and less risk factors for major osteoporotic fractures. In addition, for individuals considered frail or falls out of the ordinary caused by an unavoidable external cause (such as traffic accident or slipping outside), fracture may be inevitable and, in this sense, the fall per se may not have any significant role on such fractures.

To shed more light on these findings, we analyzed the associations between history of falls (frequency, mechanism, and severity) and site-specific fractures. According to the point estimates, previous falls (especially injurious falls) tended to increase the risk of future fractures of each of the specific sites, in particular the other fractures. However, the associations were often not statistically significant; the relatively small numbers of individual fracture types likely limited the power to detect statistical differences. Adjustment for mobility could have further clarified the findings and remains an idea for further exploration. Also, the classification of fractures into major osteoporotic vs others is not necessarily justified, since the risk for all types of fracture is increased in women with osteoporosis.

Finally, our finding, suggesting that earlier injurious falls is a strong predictor for future fracture especially for other fractures compared with major osteoporotic fractures, could be a good candidate for inclusion in fracture prediction algorithms. The current FRAX (fracture risk prediction model) screening tool includes falls; however, the inclusion of previous injurious falls in particular is likely to improve predictive power [28].

The main strength of our study was its prospective population-based design and the large study population with an overall high response rate. Some limitations are also evident. There may be possible recall biases as falls are based on self-reports [29]. In addition, we classify the mechanism of fall based on the last falling event which might affect future fracture risk estimates. Therefore, further fracture risk studies with more exact fall reporting methods and detailed information on fall mechanism would have needed to confirm the results. In the current study, the self-reported fractures were confirmed via medical reports. The former validation study of self-reported fractures in OSTPRE cohort observed the sensitivity of 
self-report to detect fracture to be $78 \%$ and specificity $96 \%$ [30]. So, it is true that some fractures may have been missed, but when a fracture was reported, it had a positive predictive value of $84 \%$ truly to be a fracture. Thus, we can assume that there was no severe recall bias involved in the self-reported fracture rates. Even further, there is no reason to believe that self-reporting would have been systematically different between the compared groups meaning that relative risks remain unbiased even though we certainly have lost some power to detect differences and therefore the study results are likely to be rather conservative. This study includes those women who responded to the fall and fracture questionnaires. The incidence of future fractures in non-responders to fall questions was same as in responders suggesting that the fracture risks related to fall history were similar in responders and non-responders. Thus, non-response to fall questions has not severely affected the future fracture risk estimations. Non-response to fracture questions is not biasing our comparisons, but generalizations beyond the population capable of answering the questionnaires should not be made without careful justifications. The current study used the major osteoporotic fracture site criteria established by FRAX and was not aiming to separate fractures due to true status of osteoporosis or trauma energy. This approach was chosen to make our finding more comparable with other similar studies using the same classification criteria. To verify osteoporotic fracture, we would have ultimately needed BMD values, but unfortunately timely BMD measurements were available only for a small fraction of this population-based cohort and detection for truly osteoporotic fractures was impossible. In order to classify women into categories of major osteoporotic and other fractures, we considered any women who had reported at least one fracture in sites of major osteoporotic fractures to belong in major osteoporotic category and women with solely other fractures to belong in other category. So, our approach allowed us to report sitespecific fracture risks in a consistent and comparable way. But as it is certainly possible that some women may have more than one fracture event, we recognize that it would be interesting to focus on that aspect in future research but that is out of scope of the current study.

In conclusion, history of falls (especially injurious falls) appeared to be an indicator for subsequent postmenopausal fracture overall. Earlier injurious falls are a stronger predictor for other fractures than for typical major osteoporotic fractures. Early identification of those at a greater risk for future fracture is the key to minimizing the associated health burden. With this knowledge, clinicians could identify those at a greater fracture risk. These findings are relevant in improving screening and prevention strategies for fractures.
Acknowledgements We would like to thank Research Secretary, Seija Oinonen, for the data management.

Funding information Open access funding provided by University of Eastern Finland (UEF) including Kuopio University Hospital. This study was funded by Finnish Cultural Foundation, Juho Vainio Foundation, and Academy of Finland. LJW is supported by a National Health and Medical Research Council (NHMRC) Career Development Fellowship (APP1064272).

\section{Compliance with ethical standards}

The ethics committee of Kuopio University Hospital approved the OSTPRE study and participants provided a written informed consent.

Conflict of interest The authors declare that they have no conflict of interests.

Open Access This article is licensed under a Creative Commons Attribution-NonCommercial 4.0 International License, which permits any non-commercial use, sharing, adaptation, distribution and reproduction in any medium or format, as long as you give appropriate credit to the original author(s) and the source, provide a link to the Creative Commons licence, and indicate if changes were made. The images or other third party material in this article are included in the article's Creative Commons licence, unless indicated otherwise in a credit line to the material. If material is not included in the article's Creative Commons licence and your intended use is not permitted by statutory regulation or exceeds the permitted use, you will need to obtain permission directly from the copyright holder. To view a copy of this licence, visit http://creativecommons.org/licenses/by-nc/4.0/.

\section{References}

1. Tinetti ME, Speechley M, Ginter SF (1988) Risk factors for falls among elderly persons living in the community. N Engl J Med 319(26):1701-1707

2. Kannus P, Niemi S, Palvanen M, Parkkari J (1997) Fall-induced injuries among elderly people. Lancet. 350(9085):1174

3. Baker SP, Harvey AH (1985) Fall injuries in the elderly. Clin Geriatr Med 1(3):501-512

4. Ray NF, Chan JK, Thamer M, Melton LJ III (1997) Medical expenditures for the treatment of osteoporotic fractures in the United States in 1995: report from the national osteoporosis foundation. $\mathrm{J}$ Bone Miner Res 12(1):24-35

5. Schwartz AV, Nevitt MC, Brown BW Jr, Kelsey JL (2005) Increased falling as a risk factor for fracture among older women: the study of osteoporotic fractures. Am J Epidemiol 161(2):180-185

6. Dargent-Molina P, Favier F, Grandjean H, Baudoin C, Schott AM, Hausherr E, Meunier PJ, Bréart G (1996) Fall-related factors and risk of hip fracture: the EPIDOS prospective study. Lancet 348(9021):145-149

7. Harvey NC, Odén A, Orwoll E, Lapidus J, Kwok T, Karlsson MK, Rosengren BE, Ljunggren Ö, Cooper C, McCloskey E, Kanis JA, Ohlsson C, Mellström D, Johansson H (2018) Falls predict fractures independently of FRAX probability: a meta-analysis of the osteoporotic fractures in men (MrOS) study. J Bone Miner Res 33(3):510-516 
8. Van Staa T, Geusens P, Kanis J, Leufkens H, Gehlbach S, Cooper C (2006) A simple clinical score for estimating the long-term risk of fracture in post-menopausal women. J Assoc Phys 99(10):673-682

9. Kelsey JL, Browner WS, Seeley DG, Nevitt MC, Cummings SR (1992) Study of osteoporotic fractures research group. Risk factors for fractures of the distal forearm and proximal humerus. Am J Epidemiol 135(5):477-489

10. Honkanen R (1982) The role of slippery weather in accidental falls. J Occup Accid 4(2-4):257-262

11. Tromp A, Smit J, Deeg D, Bouter L, Lips P (1998) Predictors for falls and fractures in the longitudinal aging study Amsterdam. J Bone Miner Res 13(12):1932-1939

12. Ensrud KE, Ewing SK, Taylor BC et al (2007) Frailty and risk of falls, fracture, and mortality in older women: the study of osteoporotic fractures. J Gerontol Ser A Biol Med Sci 62(7):744-751

13. Cumming RG, Klineberg RJ (1994) Fall frequency and characteristics and the risk of hip fractures. J Am Geriatr Soc 42(7):774-778

14. Afrin N, Honkanen R, Koivumaa-Honkanen H, Lukkala P, Rikkonen T, Sirola J, Williams LJ, Kröger H (2016) Multimorbidity predicts falls differentially according to the type of fall in postmenopausal women. Maturitas. 91:19-24

15. Afrin N, Honkanen R, Koivumaa-Honkanen H et al (2018) Role of musculoskeletal disorders in falls of postmenopausal women. Osteoporos Int 29(11):2419-2426

16. Nevitt MC, Cummings SR, Hudes ES (1991) Risk factors for injurious falls: a prospective study. J Gerontol 46(5):M164-M170

17. Kanis JA, Odén A, Johansson H, McCloskey EV (2013) Fracture risk assessment: the development and application of FRAX®. In: Marcus R, Feldman D, Dempster DW, Luckey M, Cauley JA (ed.) Osteoporosis (fourth edition). Elsevier, pp. 1611-1637

18. Center JR (2013) Outcomes following osteoporotic fractures. In: Marcus R, Feldman D, Dempster DW, Luckey M, Cauley JA (ed.) Osteoporosis (fourth edition). Elsevier, pp. 841-852

19. Randell K, Honkanen R, Kröger H, Saarikoski S (2002) Does hormone-replacement therapy prevent fractures in early postmenopausal women? J Bone Miner Res 17:528-533

20. Tinetti ME, Speechley M (1989) Prevention of falls among the elderly. N Engl J Med 320(16):1055-1059
21. Bath PA, Morgan K (1999) Differential risk factor profiles for indoor and outdoor falls in older people living at home in Nottingham, UK. Eur J Epidemiol 15(1):65-73

22. Luukinen H, Herala M, Koski K, Honkanen R, Laippala P, Kivelä $S$ (2000) Fracture risk associated with a fall according to type of fall among the elderly. Osteoporos Int 11(7):631-634

23. Tuppurainen M, Härmä K, Komulainen M, Kiviniemi V, Kröger H, Honkanen R, Alhava E, Jurvelin J, Saarikoski S (2010) Effects of continuous combined hormone replacement therapy and clodronate on bone mineral density in osteoporotic postmenopausal women: a 5-year follow-up. Maturitas. 66(4):423-430

24. Randell KM, Honkanen RJ, Komulainen MH, Tuppurainen MT, Kröger H, Saarikoski S (2001) Hormone replacement therapy and risk of falling in early postmenopausal women-a population-based study. Clin Endocrinol 54(6):769-774

25. Cummings SR, Melton LJ (2002) Epidemiology and outcomes of osteoporotic fractures. Lancet 359(9319):1761-1767

26. Nguyen TV, Center JR, Sambrook PN, Eisman JA (2001) Risk factors for proximal humerus, forearm, and wrist fractures in elderly men and women the Dubbo osteoporosis epidemiology study. Am J Epidemiol 153(6):587-595

27. Vogt MT, Cauley JA, Tomaino MM, Stone K, Williams JR, Herndon JH (2002) Distal radius fractures in older women: a 10year follow-up study of descriptive characteristics and risk factors. The study of osteoporotic fractures. J Am Geriatr Soc 50(1):97-103

28. Edwards M, Jameson K, Denison H, Harvey NC, Sayer AA, Dennison EM, Cooper C (2013) Clinical risk factors, bone density and fall history in the prediction of incident fracture among men and women. Bone. 52(2):541-547

29. Cummings SR, Nevitt MC, Kidd S (1988) Forgetting falls. J Am Geriatr Soc 36(7):613-616

30. Honkanen K, Honkanen R, Heikkinen L, Kröger H, Saarikoski S (1999) Validity of self-reports of fractures in perimenopausal women. Am J Epidemiol 150(5):511-516

Publisher's note Springer Nature remains neutral with regard to jurisdictional claims in published maps and institutional affiliations. 